\title{
Measuring Customer Satisfaction toward Localization Website by WebQual and Importance Performance Analysis (Case Study on AliexPress Site in Indonesia)
}

\author{
Ben Chang Shia, Mingchih Chen, Agus David Ramdansyah, Shuyan Wang \\ Business Administration, Fu Jen Catholic University, Taiwan \\ Email: agus.david@untirta.ac.id
}

Received 11 January 2016; accepted 21 February 2016; published 24 February 2016

Copyright (C) 2016 by authors and Scientific Research Publishing Inc.

This work is licensed under the Creative Commons Attribution International License (CC BY). http://creativecommons.org/licenses/by/4.0/

cc) (7) 0pen Access

\begin{abstract}
To better understand the effectiveness of localization across countries, we utilize WebQual method (with dimensions Usability, Information, and Service Interaction) and Importance-Performance Analysis (IPA). A website is a means of providing information, promotion and communication to customers. This study aims to analyze user perception and expectation about quality of a localized website, AliexPress. This site did localization in Indonesia market in the early of 2015. Results were measured by performance (actual) level and importance (hope) level which showed that there is a gap as a whole for all dimensions of $\mathbf{- 0 . 9 2}$. The biggest gap is in Usability dimension, -1.27. Based on this study, AliexPress website has not been able to meet user expectations, especially related to information and services contained on the website. Indicators that need more attention include providing believable information, timely information, relevant information, information at the right level of detail, feels of personal information secure, and feeling confident that goods/services will be delivered as promised. Hopefully this research would be a reference for AliexPress website management in improving service quality to face competition and answer the needs and expectations of user.
\end{abstract}

\section{Keywords}

WebQual, Importance-Performance Analysis, AliexPress

\section{Introduction}

Information technology is a part of human life today. In many areas, technology plays an important role in sup-

How to cite this paper: Shia, B.C., Chen, M., Ramdansyah, A.D. and Wang, S. (2016) Measuring Customer Satisfaction toward Localization Website by WebQual and Importance Performance Analysis (Case Study on AliexPress Site in Indonesia). American Journal of Industrial and Business Management, 6, 117-128. http://dx.doi.org/10.4236/ajibm.2016.62012 
porting all activities of human life and is able to facilitate every need of everyday human life. One example of advances in technology today is internet. It has become an integral part of human life in the 21st century. Advances in internet technology have become a symbol of how to communicate freely, without being limited by space, distance and time. Supported by connection costs which are relatively more affordable and unlimited availability of information, internet has become one of the main needs of society in fulfilling all the needs related to the information.

Internet has some advantages not only for individual users but also for organizations, for example in terms of convenience, 24 hours access a day, global reach, efficiency, alternative spaces and relatively unlimited choice, personalization, potential resources, and others. In a business context, internet brings impact of change that creates a new paradigm in business, in form of digital marketing or internet marketing (cyber marketing, electronic marketing, and a number of other terms). Internet also plays an important role in the world of economics and business. Along with the presence of e-commerce (EC), business activities can be carried out across countries. E-commerce offers greater convenience in conducting transactions.

According to Xinjiang E-commerce Development Report 2014, by the end of 2013, the world's internet users reached 2.749 billion people, equivalent to $39 \%$ of the world population, and internet penetration in developing countries reached 31 percent. Global mobile phone registered users reached 6.835 billion, closer to the number of the world's population, and wherein the number of active mobile broadband users reached 2.096 billion. Global internet penetration is expected to reach $44.88 \%$ in 2015. Global cross-border e-commerce transactions reached $\$ 105$ billion in 2013, and it is expected to reach $\$ 307$ billion within five years.

In June 2012, Indonesia ranked fourth for the number of internet users in Asia, which reached 55 million and 51 million of them have a facebook account (www.internetworldstats.com). Meanwhile, according to Indonesian Internet Service Provider Association, internet users in Indonesia reached 88.1 million people in 2014 and will keep increasing dramatically next years (www.apjii.or.id). The number of internet users in Indonesia continues to increase, and the boosted popularity of facebook makes people no longer regard that the internet is not only used for intellectual activities, but also used to create a social network. These conditions provide great opportunities for e-commerce increasingly growing in Indonesia. Social media contribute to raising public awareness of Indonesian to e-commerce.

The development of e-commerce in Indonesia is marked by the growing number of buying and selling sites quite dramatically. The term startup is used by Indonesian youth to start a business on the internet. Activities of buying and selling on the Internet begin with the activities of buying and selling forum including

www.kaskus.co.id, www.toko.nice.com, www.berniaga.com, www.bukalapak.com and other trading forums. After buying and selling forum is increasingly widespread, the concept of shopping in a mall with internet media is then grown as www.rakuten.co.id, www.lazada.co.id, www.zalora.co.id, www.blibli.com and many other online stores.

EC in Indonesia is more crowded with entry the largest online store from China, AliexPress. It is a global retail marketplace targeted at consumers worldwide, many of them located in Russia, Brazil and the United States. This website offers quality products at factory prices in small quantity. Order amount can be as low as one item. This website has officially announced that their global e-commerce now perform localization services to Indonesia since the early 2015. Indonesia itself is a very huge market for AliexPress. In 2015, this country yields a value of Rp 45.7 trillion of transactions business-to-consumer (B2C). It makes Indonesia as the fourth largest e-commerce market in Asia for B2C sales. Although there are still many things that need to be evaluated, AliexPress is able to localize in this country, such as choice of relevant products for Indonesian consumers, using Indonesia language in customer service and payment options which in 2014 recorded a transaction value of Rp 6.5 trillion (https://id.techinasia.com).

Beyond the debate about the importance of standardization and localization, this paper tries to measure Indonesia consumer satisfaction toward AliexPress website addressed in http://id.aliexpress.com with WebQual and Importance-Performance Analysis (IPA) methods. This measurement will be accorded to the perception of the Indonesian consumers of the site. Because according to Kobayashi et al. (2013) [1] perceptions of EC websites are associated not only with culture, but also with the institutional development, it is especially important to pay attention to the developmental stage of site by comparing the perceptions and expectation of user in local country. Assessments by respondents in this study are divided into two perspectives, namely website quality assessment which based on desired quality (ideal-importance) and website quality perceived (actual-performance). The level of quality can be demonstrated by calculating the value of gap between the two perspectives. In addi- 
tion, the results of this study can become a feedback for companies which will do localization especially for AliexPress. It can be used as an indicator in determining quality in accordance with the wishes of users and which require improvements of the company's website in the future.

\section{Literature Review}

\subsection{The Standardization vs. Adaptation}

There has long been a debate over the relative effectiveness of standardization and localization as international business strategies. Although the strategy of maintaining a global standard rather than localizing for each country can be effective in terms of cost savings and establishing global brand images, recent EC studies have repeatedly recognized the importance of localization of websites. Although the extant literature points to the importance of localization in cross-border e-commerce, previous studies have been largely limited to analyze the effectiveness of localization case in developing countries, especially those in Indonesia. Table 1 presents a summary of arguments from some authors about the importance of Standardization and Localization.

\subsection{WebQual}

Quality of website has become one of the strategic issues in communications and transactions with customers. WebQual is one method of measuring the quality of website developed by Stuart Barnes and Richard Vidgen. It based on the concept of Quality Function Deployment (QFD) which is a process that is based on the "voice of customer" in the development and implementation of a product or service. From the concept of QFD, WebQual compiled based on the perception of the end user to a website (Barnes and Vidgen, 2000) [2].

WebQual has undergone several iterations in category preparation and question items. The latest version is WebQual 4.0 which uses three categories (usability, information and service interaction) of measurement with 22 items of questions plus one question to measure overall quality related to IPA method as suggested by Liu et al. (2014) [3] and Chen (2014) [4]. Usability category based on user understanding in web, including ease of navigation, suitable design and picture which presented to user. Information category based on a review of information systems in general. This category relates to quality of website content that is proprietary information for user's purpose, such as accuracy, format and relevance of information. Service interaction category is related to interaction of user perception when involved deeply with website (Barnes and Vidgen, 2002) [2].

In some studies, dimensions of website quality directly affects intention to transact on an e-commerce consumers like Chen (2013) [5] found quality system, quality of information and service quality significantly influence the intention to transact on mobile shopping (m shopping). Hsiu \& Shih (2013) [6] and Yu, et al. (2009) [7] only find the quality of service that significantly. Sam and Tahir (2009) [8] examined the quality of the website such as usability, design, quality of information, trust, risk perception and empathy have significant influence on the intentions of consumers in the purchase of air tickets.

Table 1. The standardization vs. localization.

\begin{tabular}{|c|c|c|c|}
\hline \multicolumn{2}{|c|}{ Standardization } & \multicolumn{2}{|r|}{ Localization } \\
\hline Author & Arguments & Authors & Arguments \\
\hline $\begin{array}{l}\text { Quelch and Klein, 1996; } \\
\text { Petersen, Welch, and } \\
\text { Liesch 2002; Jean 2007; } \\
\text { Singh \& Boughton, 2002; } \\
\text { Kambil 1995; Sinkovics } \\
\text { and Penz 2005; Tsikriktsis, } \\
\text { 2002; Forrester Research, } \\
\text { 2001; Yip and Dempster, } \\
\text { 2005; Berthon, Pitt, and } \\
\text { Watson, } 1996\end{array}$ & $\begin{array}{l}\text { - cost savings } \\
\text { - efficiency } \\
\text { - strengthen the } \\
\text { brand image } \\
\text { - culture plays less } \\
\text { important role } \\
\text { - As a "push strategy" }\end{array}$ & $\begin{array}{l}\text { F. Vyncke, and M. Brengman, } \\
\text { 2010; K. H. Lim, K. Leung, } \\
\text { C. L. Sia, and M. K. Lee, 2004; } \\
\text { N. Singh, 2012; N. Singh and } \\
\text { D. W. Baack, 2013; N. Singh, } \\
\text { O. Furrer, and M. Ostinelli, } \\
\text { 2004; P. D. Lynch, and } \\
\text { J. C. Beck, 2001; R. R. Sinkovics, } \\
\text { M. Yamin, and M. Hossinger, } \\
\text { 2007; Kustin 2004; Katsikeas, } \\
\text { Samiee and Theodosiou 2006 }\end{array}$ & $\begin{array}{l}\text { - A product orientation, and a product driven } \\
\text { strategy solely } \\
\text { - Ignoring customer behavior and response } \\
\text { patterns and market characteristics } \\
\text { - Disadvantages in terms of vulnerability to } \\
\text { competitive attacks } \\
\text { - Lack of responsiveness to diverse } \\
\text { governmental, economical/ecological and } \\
\text { socio-cultural settings } \\
\text { - DOES NOT generate distinctiveness in } \\
\text { web-communication } \\
\text { - CAN NOT maximize market potentials in } \\
\text { respective markets } \\
\text { - Risks; losing competitive advantage. } \\
\text { pecision will depend on issues such as } \\
\text { product category, industry, competition }\end{array}$ \\
\hline
\end{tabular}




\subsection{Importance-Performance Analysis (IPA)}

Importance-Performance Analysis (IPA) is a simple and useful technique for identifying those attributes of a productor service that are most in need of improvement or that are candidates for possible cost-saving conditions without significant detriment to overall quality (Huang et al., 2015) [9].

This method was introduced by Martilla and James (1977) [10] and has been able to demonstrate the ability to provide managerial services with valuable information for measuring both satisfaction and the efficient allocation of resources in accordance with the format. This technique has been successfully used in a variety of settings to define priorities and guide resource allocation decisions (Magal and Levenburg, 2005) [11].

The aims of this method are to measure the relationship between consumer perceptions and the priority of improving the quality of products/services. It is also well known as a quadrant analysis. IPA has been generally accepted and used in various fields of study because of the ease to apply and display analysis results which facilitate performance improvement proposal. It has main function to display information relating to factors that affect customer satisfaction and loyalty, and factors that needs to be improved according to consumer opinion. For evaluating customer or user satisfaction, it is a useful and popular tool of the IPA model in many different fields, moreover, there are many research topics such as telecommunications (Park et al., 2008) [12], service quality of transportation (Ali et al., 2009) [13] and as a case study in the education field (Silva \& Fernandes, 2010) [14], (Zhu et al., 2012) [15].

IPA combines measurements of importance and satisfaction levels in two-dimensional graph that allows annotation data and gain practical proposals. Graphics IPA is divided into four quadrants based on the results of Performance-Importance measurement. According to this method, performance attributes depicted along the $\mathrm{X}$-axis and Importance attributes is depicted along the $\mathrm{Y}$-axis. Below is the explanation for each quadrant (Martilla and James, 1977) [10]:

1) The first quadrant: Maintain Performance or keep up the good work (high importance and high performance). Regarded as a supporting factor for customer satisfaction, management must ensure the performance of institution can maintain good achievements.

2) Second Quadrant: Increase Performance (high importance and low performance). Considered a very important factor, but not satisfactory for the current condition and should be a concern for management to allocate adequate resources.

3) Third Quadrant: Low Priority (low importance and low performance). Considered to have low levels of satisfaction and considered not too important by consumers, so management does not need to prioritize these factors.

4) Fourth Quadrant: Tend to Overuse (low importance and high performance). Considered not too important so that management can re-allocate the resources to other factors which more in need to be handled.

Depiction of division in IPA can be seen in Figure 1.

\section{Research Methods}

This study is quantitative descriptive. The variables and questionnaire used are based on WebQual method version 4.0 (Barnes and Vidgen, 1977) [4] consisting of usability, information, and service interaction which consists of 22 total indicators questions plus one question to measure overall quality related to IPA method as suggested by Liu et al. (2014) [3] and Chen (2014) [4], so there are 23 total items in the questionnaire (see Appendix). Cronbach's alpha was used to test the reliability of the questionnaire. The reliability coefficients of all variables are above 0.70, thus it confirms that the items used to measure are reliable. Distinguished into two types, namely quality of current perceived or actual happening (Performance) and expected quality and is considered important to develop (Importance). Observed variables as indicators in this study can be seen in Table 2 .

Process of collecting data in this research is to conduct a survey by distributing questionnaires to respondents by online and offline. Sample in this study is judgment sampling. They are Indonesia e-commerce customer who familiar with online shopping activities and who have ever made a purchase a product through AliexPress website at least one time. To get a sufficient number, the sample is not restricted by age and gender, as well as taking into account the length of time the internet usage of each respondent. Types of questions is a closed question, measured by six (6) scale ranging from strongly disagree to strongly agree. Selection of a Likert scale of one to six $(1-6)$ was chosen to reduce risk of irregularities personal decision-making and have a high reliability by eliminating scale neutral or neutral (Chomeya, 2010) [16]. 


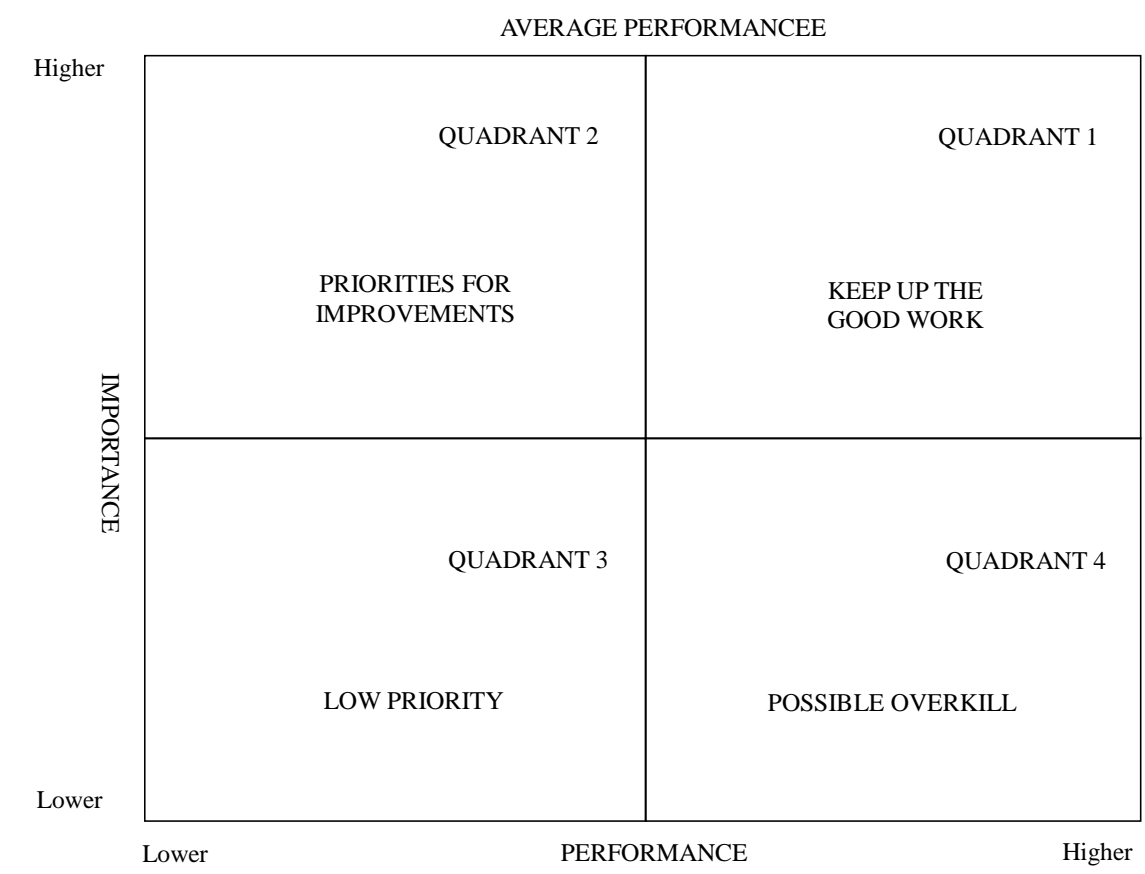

Figure 1. Quadrant IPA (Brandt, 2000).

Table 2. Assessment variable.

\begin{tabular}{|c|c|c|}
\hline Category & Indicator & Code \\
\hline \multirow{8}{*}{ Usability } & I find the site easy to learn to operate & USA1 \\
\hline & My interaction with the site is clear and understandable & USA2 \\
\hline & I find the site easy to navigate & USA3 \\
\hline & I find the site easy to use & USA4 \\
\hline & The site has an attractive appearance & USA5 \\
\hline & The design is appropriate to the type of site & USA6 \\
\hline & The site conveys a sense of competency & USA7 \\
\hline & The site creates a positive experience for me & USA8 \\
\hline \multirow{7}{*}{ Information } & Provides accurate information & INF1 \\
\hline & Provides believable information & INF2 \\
\hline & Provides timely information & INF3 \\
\hline & Provides relevant information & INF4 \\
\hline & Provides easy to understand information & INF5 \\
\hline & Provides information at the right level of detail & INF6 \\
\hline & Presents the information in an appropriate format & INF7 \\
\hline \multirow{7}{*}{ Service interaction } & Has a good reputation & INF8 \\
\hline & It feels safe to complete transactions & SERV1 \\
\hline & My personal information feels secure & SERV2 \\
\hline & Creates a sense of personalization & SERV3 \\
\hline & Conveys a sense of community & SERV4 \\
\hline & Makes it easy to communicate with the organization & SERV5 \\
\hline & I feel confident that goods/services will be delivered as promised & SERV6 \\
\hline Overall quality & Consumers satisfaction of overall website quality & OQ \\
\hline
\end{tabular}


Number of samples used is as many as 90 respondents, where they are selected from among students. Selection of student as respondents due to segmentation of who have used AliexPress site. Data was collected by distributing questionnaires in several online forums and social media which is considered as a suitable place to get respondents as defined sample characteristics for this study. We also distribute questionnaires directly on campuses to capture right respondents.

\section{Results and Data Analysis}

Characteristics of respondents composed of $90 \%$ men and 10\% women. Segmentation based on age, $75 \%$ are between the ages of 21 - 25 years and 25\% were under the age of 20 years. Based on duration of using internet, as many as $41.67 \%$ of respondents spent more than 5 hours a day, $38.33 \%$ of respondents spend $1-3$ hours a day and $20 \%$ spend 3 - 5 hours a day to use the internet.

Below is Table 3 which illustrates indicators used in this study after the validity and reliability along with each value of importance and performance.

Table 3. Indicator value.

\begin{tabular}{|c|c|c|c|}
\hline Code & Indicator & Imp & Perf \\
\hline USA1 & I find the site easy to learn to operate & 5.43 & 4.65 \\
\hline USA2 & My interaction with the site is clear and understandable & 5.28 & 4.43 \\
\hline USA3 & I find the site easy to navigate & 5.20 & 4.45 \\
\hline USA4 & I find the site easy to use & 5.02 & 4.53 \\
\hline USA5 & The site has an attractive appearance & 5.18 & 4.75 \\
\hline USA6 & The design is appropriate to the type of site & 5.18 & 4.33 \\
\hline USA7 & The site conveys a sense of competency & 5.21 & 4.85 \\
\hline USA8 & The site creates a positive experience for me & 5.25 & 3.98 \\
\hline INF1 & Provides accurate information & 5.25 & 4.12 \\
\hline INF2 & Provides believable information & 5.27 & 4.25 \\
\hline INF3 & Provides timely information & 5.28 & 4.35 \\
\hline INF4 & Provides relevant information & 5.28 & 4.27 \\
\hline INF5 & Provides easy to understand information & 5.32 & 4.67 \\
\hline INF6 & Provides information at the right level of detail & 5.33 & 4.28 \\
\hline INF7 & Presents the information in an appropriate format & 5.18 & 4.20 \\
\hline INF8 & Has a good reputation & 5.47 & 4.95 \\
\hline SERV1 & It feels safe to complete transactions & 5.25 & 4.08 \\
\hline SERV2 & My personal information feels secure & 5.27 & 4.22 \\
\hline SERV3 & Creates a sense of personalization & 5.30 & 4.73 \\
\hline SERV4 & Conveys a sense of community & 5.32 & 4.70 \\
\hline SERV5 & Makes it easy to communicate with the organization & 5.28 & 4.40 \\
\hline SERV6 & I feel confident that goods/services will be delivered as promised & 5.28 & 4.36 \\
\hline \multirow[t]{2}{*}{ OQ } & Consumers satisfaction of overall website quality & 5.27 & 4.10 \\
\hline & Mean & 5.27 & 4.42 \\
\hline
\end{tabular}

Description: Imp (Importance) and Perf (Performance). 
Gap analysis is applied to see gap between perceived quality (actual) and expected quality (ideal). Actual quality is demonstrated through respondents assessment of the performance attribute indicator forming quality website based dimension WebQual indicator, while the ideal qualities shown by respondents assessment of expectations (importance) of attributes of quality indicators. Process for determining gap value can be calculated from difference of actual quality value (Performance) and ideal quality value (Importance).

$\mathrm{Q}(\mathrm{Gap})=$ Perf - Imp

Description:

Gap = Level of the quality gap

Perf $=$ Value of current perceived or actual quality (performance)

Imp = Value of ideal quality or expectation and need to be developed (importance)

Good quality levels signified by a positive value or $Q \geq 0$. This signifies actual quality has met ideal quality that is expected by the respondents. Conversely if the results of $\mathrm{Q}<0$ or negative, the quality level is not able to meet desires of user. Below are tables of gap value of each dimension (usability, information and service interaction).

Table 4 shows the value of usability gap. It can be seen that the value of the difference between the actual quality (performance) and ideal quality (importance) of all of the indicators is negative. The difference of average gap is -0.72 . Indicators that have the biggest gap is in USA8 "The site creates a positive experience for me" with a gap difference of -1.27 .

Table 5 shows value of dimension information gap. Based on the table, it can be seen that the value of difference between actual quality (performance) and ideal quality (importance) of all indicator is negative with gap average of -0.91 . The biggest gap is in the variable INF1 "Provides accurate information" by a margin gap of -1.13 .

Table 4. Value of usability gaps.

\begin{tabular}{|c|c|c|c|c|}
\hline Variable & Indicator & Imp & Perf & $\mathrm{Q}($ Gap) \\
\hline USA1 & I find the site easy to learn to operate & 5.43 & 4.65 & -0.78 \\
\hline USA2 & My interaction with the site is clear and understandable & 5.28 & 4.43 & -0.85 \\
\hline USA3 & I find the site easy to navigate & 5.20 & 4.45 & -0.75 \\
\hline USA4 & I find the site easy to use & 5.02 & 4.53 & -0.49 \\
\hline USA5 & The site has an attractive appearance & 5.18 & 4.75 & -0.43 \\
\hline USA6 & The design is appropriate to the type of site & 5.18 & 4.33 & -0.85 \\
\hline USA7 & The site conveys a sense of competency & 5.21 & 4.85 & -0.36 \\
\hline \multirow[t]{2}{*}{ USA8 } & The site creates a positive experience for me & 5.25 & 3.98 & -1.27 \\
\hline & Mean & 5.22 & 4.50 & -0.72 \\
\hline
\end{tabular}

Table 5. Value of information gaps.

\begin{tabular}{|c|c|c|c|c|}
\hline Variable & Indicator & Imp & Perf & $\mathrm{Q}(\mathrm{Gap})$ \\
\hline INF1 & Provides accurate information & 5.25 & 4.12 & -1.13 \\
\hline INF2 & Provides believable information & 5.27 & 4.25 & -1.02 \\
\hline INF3 & Provides timely information & 5.28 & 4.35 & -0.93 \\
\hline INF4 & Provides relevant information & 5.28 & 4.27 & -1.01 \\
\hline INF5 & Provides easy to understand information & 5.32 & 4.67 & -0.65 \\
\hline INF6 & Provides information at the right level of detail & 5.33 & 4.28 & -1.05 \\
\hline INF7 & Presents the information in an appropriate format & 5.18 & 4.20 & -0.98 \\
\hline INF8 & Has a good reputation & 5.47 & 4.95 & -0.52 \\
\hline & Mean & 5.30 & 4.39 & -0.91 \\
\hline
\end{tabular}


Table 6 shows the value of gap in service interaction. As with the previous two-dimensional, where the differences of all the indicators in this dimension is negative. The differences of the average gap of -0.87 . Indicators that have the biggest gap is in the variable SERV1 "It feels safe to complete transactions" with the difference gap of -1.17 .

Table 7 shows the value of gap in overall quality which has gap difference of -1.17 .

Table 8 shows a gap value of three-dimensional WebQual plus overall quality. Based on above table, the difference gap value between actual quality (performance) and ideal quality (importance) has a negative value, -0.92 . Beyond overall quality, the largest gap of three-dimensional WebQual is information with a difference of -0.91 . The results showed $\mathrm{Q}<0$, which means that actual quality perceived is not able to meet the desired quality of user, so quality is not good enough.

Importance-Performance Analysis (IPA) is a simple and useful technique for identifying those attributes of a product or service that are most in need of improvement or that are candidates for possible cost-saving conditions without significant detriment to overall quality (Abalo, 2006) [17]. Results of IPA analysis show location of each indicator in IPA matrix consisting of four quadrants. The average value from Table 3 is applied to process of determining the coordinates for each indicator. Figure 2 shows the position of indicators in IPA matrix, where each dimension is depicted with each label.

Based on Figure 2, it can be seen the position of each indicators in IPA matrix. Each quadrant has a specific interpretation with strategic actions which explain what should be done for each indicator. Based on the position of each quadrant, it can be seen that USA1, USA2, SERV3, SERV4, INF5 and INF8 are located in quadrant 1. These indicators are considered have high importance and performance level. Indicators which located in this quadrant have suitability with user wishes and should be maintained or keep up the good work.

INF2, INF3, INF4, INF6, SERV2, SERV6, and OQ are located in quadrant 2 which mean that those indicators are not in accordance with expectations of users. Those indicator are considered to have a high level of

Table 6. Value indicator service interaction gaps.

\begin{tabular}{|c|c|c|c|c|}
\hline Variable & Indicator & Imp & Perf & $\mathrm{Q}(\mathrm{Gap})$ \\
\hline SERV1 & It feels safe to complete transactions & 5.25 & 4.08 & -1.17 \\
\hline SERV2 & My personal information feels secure & 5.27 & 4.22 & -1.05 \\
\hline SERV3 & Creates a sense of personalization & 5.30 & 4.73 & -0.57 \\
\hline SERV4 & Conveys a sense of community & 5.32 & 4.70 & -0.62 \\
\hline SERV5 & Makes it easy to communicate with the organization & 5.28 & 4.40 & -0.88 \\
\hline \multirow[t]{2}{*}{ SERV6 } & I feel confident that goods/services will be delivered as promised & 5.28 & 4.36 & -0.92 \\
\hline & Mean & 5.28 & 4.42 & -0.87 \\
\hline
\end{tabular}

Table 7. Overall quality gaps.

\begin{tabular}{c|cccc}
\hline Variable & Indicator & Imp & Perf & Q(Gap) \\
\hline OQ & Consumers satisfaction of overall website quality & 5.27 & 4.10 \\
\hline
\end{tabular}

Table 8. Gaps value all indicators.

\begin{tabular}{cccc}
\hline Indicator & Imp & Perf & -0.72 \\
Usability & 5.22 & 4.50 & -0.91 \\
Information & 5.30 & 4.39 & -0.87 \\
Service Interaction & 5.28 & 4.42 & -1.17 \\
Overall Quality & 5.27 & 4.35 & -0.92 \\
Mean & 5.27 & & 4.35
\end{tabular}




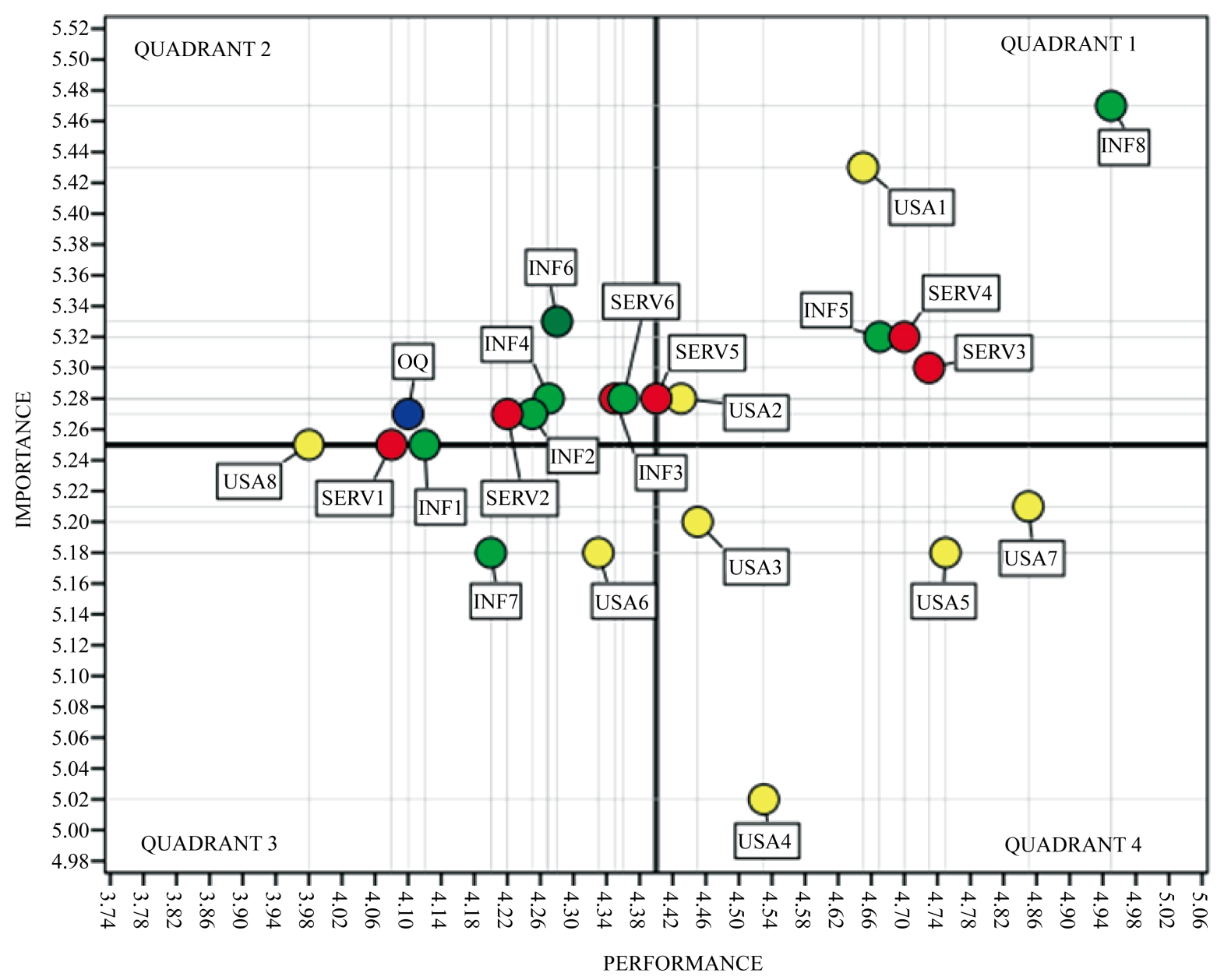

Figure 2. Diagram Importance-Performance Analysis (IPA).

importance, but performance level is low so they are key priority to be improved. However SERV5 is in the midst quadrants 1 and 2. This indicator located between high and low performance, but based on user perception, it is in high importance level.

USA6 and INF7 located in quadrant 3. From user perception, these indicators have low importance level and low performance level. They are considered as not top priority to be improved. However USA8, SERV1 and INF1 are in the midst quadrants 2 and 3. These three indicators located between high and low importance level, but based on user perception, they are in low performance level.

The last indicators are USA3, USA4, USA5 and USA7 which located in quadrant 4 where these indicators are considered to have a low rate of importance, but performance level are rated as excellent by the user. They are assessed have far exceeded user expectations.

\section{Discussion}

Based on results of this study, there is a difference of average value assessment between actual quality (performance) and ideal quality (importance) of www.aliexpress.co.id. This shows that there is a gap between two perspectives. From Table 8, we can see that gap value of all indicators is negative which indicate that actual quality (performance) does not meet user expected quality (importance). The largest gap value of three quality attributes are "The site creates a positive experience for me" with the difference gap of -1.27 , "Provides accurate information" value gap difference of -1.13 and "It feels safe to complete transactions" with the value of the difference gap of -1.17 . While all mean of the three dimensions of WebQual, information having the largest gap difference with value of -0.91 . 
The following is an analysis based on division of each quadrant based on Figure 2:

- Quadrant 1:

USA1 (I find the site easy to learn to operate), USA2 (My interaction with the site is clear and understandable), SERV3 (Creates a sense of personalization), SERV4 (Conveys a sense of community), INF5 (Provides easy to understand information) and INF8 (Has a good reputation). In this quadrant, user has high importance level (expectation) and company has shown a good performance (actual). Indicators in this quadrant are considered in accordance with the wishes of users and should be maintained or keep up the good work.

- Quadrant 2:

INF2 (Provides believable information), INF3 (Provides timely information), INF4 (Provides relevant information), INF6 (Provides information at the right level of detail), SERV2 (My personal information feels secure), SERV6 (I feel confident that goods/services will be delivered as promised), and OQ (Consumers satisfaction of overall website quality). In this quadrant indicators are not in accordance with the expectations of users and has a high level of importance (high expectations), but the level of performance (actual) is considered low and these indicators are expected a top priority to develop in the future.

- Quadrant 3:

USA6 (The design is appropriate to the type of site) and INF7 (Presents the information in an appropriate format). In this quadrant according to the user's perception, both indicators of importance (expectation) and performance (actual) level are low. Indicators in this quadrant are considered in compliance developed by AliexPress and not considered as a top priority to be improved.

- Quadrant 4:

USA3 (I find the site easy to navigate), USA4 (I find the site easy to use), USA5 (The site has an attractive appearance), USA7 (The site conveys a sense of competency). In this quadrant, users perceived that the indicator is considered to have low importance level (expectation) but company has good performance (actual). Indicators in this quadrant are considered to have far exceeded expectations of users. This quadrant implies that the resources would be better used in others, because high performance considered irrelevant indicate a possible exaggeration.

- Intersect:

USA8 (The site creates a positive experience for me), SERV1 (It feels safe to complete transactions) and INF1 (Provides accurate information) are in the midst quadrants 2 and 3. These three indicators located between high and low importance level, but based on user perception, they are in low performance level. SERV5 (Makes it easy to communicate with the organization) where located between quadrants 1 and 2 illustrate that this quality has a high importance level (expectation) and has average performance level. This study shows the need for management of the website AliexPress efforts in improving the quality of the website in order to meet the suitability of the users.

This study has some limitations. First of all, this study only measure localized AliexPress site toward Indonesia customer satisfaction. Future studies can extend to other localized sites in other countries to improve the generality of the model. Secondly, this study has intention to understand the perception of Indonesia e-commerce consumer related to foreign sites especially AliexPress. Future studies can consider to understand the perception of other localized sites, and investigate if the WebQual method could be important for localized site. Lastly, additional indicators can be included in future research models.

\section{Conclusions}

Based on results of evaluation AliexPress website using WebQual and Importance-Performance Analysis (IPA), it can be concluded that some quality of AliexPress website does not meet user expectations. There are difference values that show gaps between performance assessment or actual quality and importance level or ideal quality that user expected. The difference of both the perspective of this assessment or gap is negative with a value of -0.92 . Based on the assessment of the three-dimensional measurement, usability dimension has a gap value of -0.72 ; information dimension has a gap value of -0.91 which is the greatest of three WebQual dimension; service interaction dimensions has a gap value of -0.87 and overall quality is -1.17 . From this result, we can conclude that actual perceived quality does not meet desired ideal quality of AliexPress user in Indonesia, mainly quality associated with information in website.

According to analysis of four quadrants, the development could be focused on the quality attributes of the in- 
formation and service interaction, especially from the aspects of providing believable information, providing timely information, providing relevant information, and providing information at the right level of detail. My personal information feels secure and I feel confident that goods/services will be delivered as promised where they are located in quadrant 2 . These attributes require more attention because of the higher expectations of users. In improvement or development of these attributes, it would be wise to consider the elements which are associated with localization strategy including the culture and behavior of local users.

\section{References}

[1] Kobayashi, T., Okada, H., Cooharojananone, N., Bracamonte, V. and Suzuki, T. (2013) How Can Electronic Commerce in Developing Countries Attract Users from Developed Countries? A Comparative Study of Thailand and Japan. International Journal of Electronic Commerce Studies, 4, 159-184. http://dx.doi.org/10.7903/ijecs.1105

[2] Barnes, S. and Vidgen, R. (2002) An Integrative Approach to the Assessment of E-Commerce Quality. Journal of Electronic Commerce Research, 3, 114-127.

[3] Liu, H.-C., Jeng, B.-C., Mai, Y.-T., Jheng, Y.-D. and Lin, H.-T. (2014) Design of Online Survey System with an Advanced IPA Discrimination Index for Customer Satisfaction Assessment. Electronic Commerce Research, 14, $223-243$. http://dx.doi.org/10.1007/s10660-014-9141-8

[4] Chen, L.-F. (2013) A Novel Framework for Customer-Driven Service Strategies: A Case Study of a Restaurant Chain. Tourism Management, 41, 119-128. http://dx.doi.org/10.1016/j.tourman.2013.09.003

[5] Chen, L.Y. (2013) The Quality of Mobile Shopping System and Its Impact on Purchase Intention and Performance. International Journal of Managing Information Technology (IJMIT), 5, 23. http://dx.doi.org/10.5121/ijmit.2013.5203

[6] Hsiu, H.C. and Shih, W.H. (2013) Exploring Antecedents and Consequence of Online Group-Buying Intention: An Extended Perspective on Theory of Planned Behavior. International Journal of Information Management, 33, 185-198. http://dx.doi.org/10.1016/j.ijinfomgt.2012.09.003

[7] Lee, Y.-J., Huang, C.-L., Chang, L.-Y. and Chen, C.-Y. (2009) Exploring the Influence of Online Consumers’ Perception on Purchase Intention as Exemplified with an Online Bookstore. Journal of Global Business Management, 5.

[8] Sam, M. and Tahir, H. (2009) Website Quality and Consumer Online Purchase Intention of Air Ticket. International Journal of Basic \& Applied Sciences IJBAS, 9.

[9] Huang, Y.-K., Fan, W.-S., Tsai, M.-C. and Ho, Y.-H. (2015) Using Importance-Performance Analysis in Evaluating Taiwan Blog E-Service Quality. Journal of Economics, Business and Management, 3, 338-345. http://dx.doi.org/10.7763/JOEBM.2015.V3.206

[10] Martilla, J.A. and James, J.C. (1977) Importance-Performance Analysis. Journal of Marketing, 41, 77-79. http://dx.doi.org/10.2307/1250495

[11] Magal, S.R. and Levenburg, N.M. (2005) Using Importance-Performance Analysis to Evaluate E-Business Strategies among Small Businesses. IEEE Proceedings of the 38th Hawaii International Conference on System Sciences, Big Island, HI, 3-6 January 2005, 176a.

[12] Park, Y.J., Heo, P.S., Rim, M.H. and Park, D.S. (2008) Customer Satisfaction Index Measurement and ImportancePerformance Analysis for Improvement of the Mobile RFID Services in Korea. Proceedings of the International Conference on Management of Engineering \& Technology (PICMET 2008), Portland, 27-31 July 2008, 2657-2665. http://dx.doi.org/10.1109/PICMET.2008.4599895

[13] Ali, Z.M., Ismail, M., Suradi, N.R.M. and Ismail, A.S. (2009) Importance-Performance Analysis and Customer Satisfaction Index for Express Bus Services. Proceedings of the World Congress on Nature \& Biologically Inspired Computing (NaBIC 2009), Coimbatore, 9-11 December 2009, 590-595. http://dx.doi.org/10.1109/NABIC.2009.5393416

[14] Silva, F. and Fernandes, P. (2010) Using Importance-Performance Analysis in Evaluating Institutions of Higher Education: A Case Study. Proceedings of the 2010 International Conference on Education and Management Technology (ICEMT), Cairo, 2-4 November 2010, 121-123. http://dx.doi.org/10.1109/ICEMT.2010.5657689

[15] Zhu, Z., Zhu, T., Zhu, Y. and Sun, M. (2012) Study on Effective Assessment of Practical Teaching in University Based on IPA. Lecture Notes in Electrical Engineering, 111, 391-398. http://dx.doi.org/10.1007/978-3-642-24823-8_61

[16] Chomeya, R. (2010) Quality of Psychology Test between Likert Scale 5 and 6 Points. Journal of Social Sciences, 6, 399-403. http://dx.doi.org/10.3844/jssp.2010.399.403

[17] Abalo, J., Varela, J. and Manzano, V. (2007) Importance Values for Importance-Performance Analysis: A Formula for Spreading out Values Derived from Preference Rankings. Journal of Business Research, 60, 115-121. http://dx.doi.org/10.1016/j.jbusres.2006.10.009 


\section{Appendix. Questionnaire}

Please indicate your agreement or disagreement with the following statements:

Rating scale

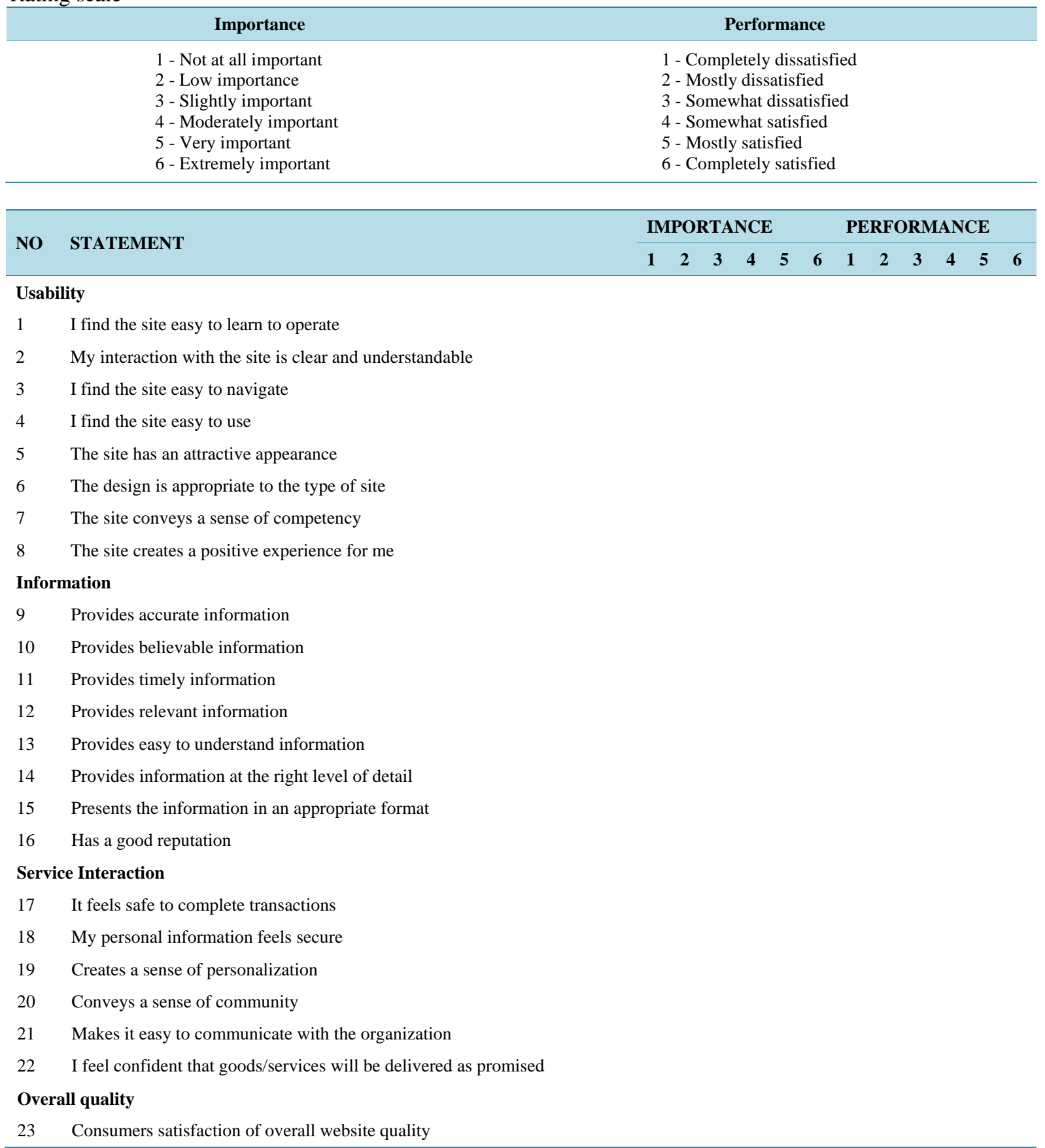

